Anne-Joëlle Bosset Murone and Aki Kawasaki*

\title{
Rowland Payne syndrome in a neonate as a consequence of birth trauma
}

\section{Abstract}

Background: The syndrome of Rowland Payne is a rare triad of unilateral Horner syndrome, ipsilateral vocal cord paralysis, and ipsilateral paralysis of the hemidiaphragm.

Case: A healthy newborn was noted to have right ptosis, a weak hoarse cry, and stridor immediately following delivery with forceps. Pupillary miosis on the same side as the ptosis was observed. Chest X-ray showed elevation of the right diaphragmatic dome. A diagnosis of Rowland Payne syndrome was made. Neuroimaging did not reveal any structural mass lesions. The hoarseness and stridor resolved within 1 month without intervention. The Horner syndrome improved but did not disappear completely.

Conclusion: In the few reported cases in the literature, the cause of Rowland Payne syndrome has been a malignant lesion of the anterior neck disrupting the oculosympathetic nerve, the vagus nerve, and the phrenic nerve. This is the first report of Rowland Payne syndrome in a neonate. We did not find any malignancy or compressive lesion to account for his symptoms and signs. We suggest that shearing forces at the lower neck at the level of the clavicle caused stretching and mechanical injury to these motor nerves or their branches. In this report of Roland Payne syndrome related to birth trauma, the prognosis was favorable.

Keywords: Birth trauma; hoarseness; Horner syndrome; pupils; Rowland Payne syndrome; stridor.

DOI 10.1515/crpm-2014-0011

Received February 26, 2014. Accepted July 21, 2014. Previously published online August 13, 2014.

*Corresponding author: Aki Kawasaki, Jules Gonin Eye Hospital, Avenue de France 15, 1004 Lausanne Switzerland,

Tel: +4121626 8660, Fax: +41216268666,

E-mail: aki.kawasaki@fa2.ch

Anne-Joëlle Bosset Murone: Cabinet Bosset-Thurler, Lausanne, Switzerland

Aki Kawasaki: Department of Ophthalmology, University of Lausanne, Fondation Asile des Aveugles and Jules Gonin Eye

Hospital, Lausanne, Switzerland

\section{Introduction}

In the Journal of the Royal Society of Medicine in 1981, Dr. Rowland Payne described three women with metastatic breast cancer who had hoarseness and unilateral shoulder pain [4]. Each had an unusual triad of clinical findings: unilateral Horner syndrome, ipsilateral vocal cord paralysis, and paralysis of the ipsilateral hemidiaphragm. Compression of the sympathetic, vagus, and phrenic nerves by a single lesion (metastasis) in the anterior neck was the distinctive feature of this syndrome. All three patients died soon thereafter, prompting the suggestion that the appearance of these clinical signs in the setting of malignancy signals a grave prognosis.

There have been only two additional publications of Rowland Payne syndrome in the English literature $[1,3]$. These additional patients also had a malignant cancer, which furthered the impression that this syndrome is a marker of serious underlying pathology. Herein, we describe a neonate who had symptoms at birth consistent with Rowland Payne syndrome, which was most likely related to head and neck manipulation during delivery.

\section{Case report}

The patient was a newborn boy delivered by spontaneous vaginal delivery at 41 weeks of gestation after a normal pregnancy. An occiput posterior presentation was noted. Delivery of the fetus required manual manipulation and use of forceps for nonprogression. Apgar scores were 5 and 8 at 1 and $5 \mathrm{~min}$, respectively, and mask ventilation was required for $30 \mathrm{~s}$ to produce a first cry at $90 \mathrm{~s}$. Birth weight was $3.37 \mathrm{~kg}$, length $51 \mathrm{~cm}$, and head circumference $34.5 \mathrm{~cm}$.

In the first hour after birth, the newborn had a weak hoarse cry and inspiratory stridor. The stridor persisted for $48 \mathrm{~h}$ and, thereafter, became intermittent. Following otolaryngologic examination, vocal cord paralysis was presumed causative, though formal laryngoscopy was not performed as the stridor was spontaneously improving. Feeding problems were not encountered. Caput succedaneum, occipitoparietal plagiocephaly on the left side, and 
torticollis were present and all attributed to birth trauma. There was no paralysis of the face, hand, or arm. The parents mentioned a right upper lid ptosis.

Following discharge on day 4, the pediatrician confirmed a right ptosis and also found an anisocoria. The smaller pupil was on the same side as the ptosis. Ocular motility was normal. The torticollis was improved, and an indurated mass on the belly of the right sternocleidomastoid muscle, consistent with a calcified traumatic hematoma, was noted. A clinical diagnosis of right Horner syndrome was confirmed pharmacologically with $4 \%$ topical cocaine. Magnetic resonance imaging of the head, neck, and thorax revealed no structural lesion. At 1 month of age, the patient was growing and developing normally. His stridor and torticollis had resolved completely. A chest X-ray showed mild elevation of the right diaphragm. Diaphragmatic motility was normal, however, by ultrasound.

\section{Discussion}

The syndrome of Rowland Payne is a palsy of three motor nerves on the same side: the oculosympathetic nerve, the vagus nerve (or recurrent pharyngeal nerve), and the phrenic nerve. Symptoms and signs are few, subtle, and easily overlooked. Initial symptoms are typically hoarseness of voice and/or shoulder pain $[1,3,4]$. In one patient, dysphagia was an important early manifestation [1]. In the only published case of an infant with Rowland Payne syndrome, the clinical presentation was more dramatic with intermittent cough and respiratory distress progressing to hoarseness, stridor, posturing, and fever [3].

The sympathetic, vagus, and phrenic nerves travel in close proximity in a small area posterior to the carotid sheath, which is anterolateral to the origin of the anterior scalene muscle and medial to the lymphatic chain of the internal jugular vein [4]. In prior reports, the causative lesion was a malignant mass in the anterior neck at the level of C6. [1.3]. In our patient, neuroimaging disclosed no structural lesion. We believe the location of injury causing Rowland Payne syndrome in our patient was the lower neck, not the upper anterior neck as originally reported. In the lower neck, there is right-left asymmetry of the pathway of several nerves. The right recurrent laryngeal nerve branches off the vagus nerve and passes under the subclavian artery, whereas the left recurrent laryngeal nerve passes under the aortic arch. The right, but not left, phrenic nerve crosses the subclavian artery as it arises from the brachiceophalic artery, accounting for the fact that $70-80 \%$ of acquired phrenic nerve palsies in neonates occur on the right side, as in our patient $[2,5]$. Under the subclavian artery also passes the ansa subclavius of the sympathetic nerve. In the absence of a structural lesion of the neck or mediastinum, we suggest that excessive stretching or shearing of the motor nerves in the lower neck and supraclavicular fossa may cause Rowland Payne syndrome in the neonate. Because of the anatomic asymmetry of the pathway of the right and left phrenic and vagus nerves in the lower neck, the majority of Rowland Payne syndrome due to birth trauma or other lesions in the lower neck can be expected to occur on the right side.

In conclusion, we present a case of Rowland Payne syndrome in a neonate. Suspicion of this diagnosis is raised when congenital Horner syndrome is associated with hoarseness, stridor, or respiratory distress. Appropriate investigation of the vocal cords and diaphragm should be considered. Imaging studies should be performed to rule out a structural cause of Rowland Payne syndrome, and if none is found, birth trauma may be the pathophysiologic mechanism. In such cases of birth trauma-related Rowland Payne syndrome, the prognosis is more favorable than that reported with malignancy-related Rowland Payne syndrome.

Funding source: None.

Financial disclosure: The authors have no financial relationships relevant to this article.

\section{References}

[1] Amin R. Horner's syndrome with ipsilateral vocal cord and phrenic nerve palsies. Postgrad Med J. 1984;60:140-2.

[2] Hughes CA, Harley EH, Milmoe G, Bala R, Martorella A. Birth trauma in the head and neck. Arch Otolaryngol Head Neck Surg. 1999;125:193-9.

[3] Kapoor V, Agarwala S. Superior mediastinal syndrome with Rowland-Payne syndrome: an unusual presentation of cervico-mediastinal neuroblastoma. Pediatr Blood Cancer. 2005;44:280-2.

[4] Rowland Payne CME. Newly recognized syndrome in the neck: Horner's syndrome with ipsilateral vocal cord and phrenic nerve palsies. J Royal Soc Med. 1981;74:814-8.

[5] Stramrood CAI, Blok CA, van der Zee DC, Gerards LJ. Neonatal phrenic nerve injury due to traumatic delivery. J Perinat Med. 2009;37:293-6.

The authors stated that there are no conflicts of interest regarding the publication of this article. 